\title{
Converting TSX 300 Index to S\&P/TSX Composite Index: Effects on the Index's Capitalization and Performance
}

\author{
Shamsul Alam ${ }^{1}$, Ebenezer Asem ${ }^{1} \&$ Shirin Shams ${ }^{1}$ \\ ${ }^{1}$ Faculty of Management, University of Lethbridge, Lethbridge, Alberta, Canada \\ Correspondence: Ebenezer Asem, Faculty of Management, University of Lethbridge, Lethbridge, AB, T1K 3M4, \\ Canada. Tel: 1-403-382-7142. E-mail: ebenezer.asem@uleth.ca
}

Received: March 10, 2016

Accepted: April 12, 2016

Online Published: May 25, 2016

doi:10.5539/ijef.v8n6p250

URL: http://dx.doi.org/10.5539/ijef.v8n6p250

\begin{abstract}
In May 2002, the TSX (Toronto Stock Exchange) 300 Index was converted to S\&P/TSX Composite Index, increasing the flexibility of stock addition to, and deletion from, the Index. We study whether the increased flexibility enhances the Index's ability to mimic the Canadian equity market performance and to represent the equity market. Our results show that the S\&P/TSX Composite Index captures a higher proportion of the equity market and has a lower tracking error than the TSX 300 Index. This suggests that flexibility in updating the constituents of an index is an important determinant of the index's ability to represent the underlying market.
\end{abstract}

Keywords: index performance, S\&P/TSX index, TSX 300 index, event studies

\section{Introduction}

The Toronto Stock Exchange (TSX) 300 Index, launched in January 1977, is a market value-weighted Index comprising 300 of the largest stocks traded on the TSX. A major equity index, such as the TSX 300, fulfills several functions. This includes capturing a large proportion of the underlying equity market's capitalization and serving as a performance benchmark for professional investment managers. To act as a suitable performance benchmark for Canadian investment managers, the TSX 300 Index's performance should closely track the Canadian equity market's performance and, to represent the Canadian equity market, the Index must capture a high percentage of the Canadian equity market's capitalization.

In May 2002, the management of TSX 300 was taken over by the Standard \& Poor's, and the Index was converted to S\&P/TSX Composite Index. A key reason for the conversion is that several stocks in the Index were non-performing with low market capitalization. For instance, Bloom and Blackwell (2002) report that the bottom 100 stocks in the TSX 300 represented less than 3\% of the Index. Glenn Doody, director of Canadian index services for Standard \& Poor's, said and we quote:

"The changes will address two main functions of a good benchmark - it must be investable and it must be representative of a fund manager's portfolio. Given that many fund managers limit their investments to companies in the top two-thirds of the Index, these changes will ensure that the Index will serve Canadian investors well" (Bloom \& Blackwell, 2002).

To address this, the number of stocks in the Index is no longer fixed at 300, but is allowed to float (no specific number required), and stocks can be added to or deleted from the Index more frequently (i.e., updating was changed from annually to quarterly). Also, industries were reclassified from fourteen sectors to ten sectors (Note 1). These key changes increased the flexibility of stock additions to, and deletions from, the Index. As a result of this flexibility, the Index Committee deleted 82 stocks and added 14 stocks from June to December 2002, reducing the number of stocks in the Index from 300 to 232 over the six months following the conversion event.

The conversion, and the accompanying increase in flexibility in stock addition to, and deletion from, the Index raises the question of whether the increased flexibility enhances the two major functions of the Index. That is, does the new Index capture a higher proportion of the Canadian equity market and does it reduce the tracking error? We focus on these questions and we find that the return on S\&P/TSX Composite Index more accurately tracks the equity market return than its predecessor, the TSX 300 Index. Also, S\&P/TSX Composite Index captures a higher percentage of the Canadian equity market than TSX 300 Index. These results suggest that the increased flexibility associated with the new Index enhances the Index's ability to perform these key functions. 
Stock additions to and deletions from an Index have attracted the attention of several researchers. These researchers have, however, focused on explaining the positive price reactions to stock additions and the negative reaction to stock deletions (Note 2). In contrast to these studies, we focus on the effects of flexibility in stock addition to, or deletion from, an Index on the Index's ability to represent and mimic the performance of the underlying market. A few studies have examined the effects of changes in the S\&P 500 Index constituents on the performance of the Index. Foster and Kaplan (2001) and Siegel and Schwartz (2006) compare the performance of the original S\&P 500 stocks (stocks in 1957) to that of the updated Index to examine whether updating the Index (i.e., deleting and adding stocks) enhances its performance. Foster and Kaplan (2001) find that updating the Index results in a stronger performance than buying and holding the original S\&P 500 stocks. In contrast, Siegel and Schwartz (2006) report a higher return for the original S\&P 500 stocks than the updated Index. The difference in conclusions is driven by a difference in computing the Index's return. Foster and Kaplan compute the Index's return as the increase in capitalization relative to the preceding period's capitalization, while Siegel and Schwartz compute the return as the market value-weighted return of the stocks in the Index. Since low capitalization stocks are usually replaced by high capitalization stocks in the Index, Foster and Kaplan obtain a stronger performance for the updated Index than the original stocks in the Index.

Asem and Alam (2012) examine the effect of stock addition to or deletion from the S\&P 500 Index on the Index's ability to track the U.S. equity market's performance. They find that the S\&P 500 Index Committee captures a large fraction of the U.S. equity market by maintaining high-capitalization stocks despite the fact that these stocks underperform the Index by $0.24 \%$ per month. The Index Committee compensates for the underperformance by substituting high-performing stocks for smaller non-performing stocks. This suggests that stock additions to, and deletions from, the S\&P 500 Index are essential for the Index to capture a high fraction of the U.S. equity market (an average of 73\% from 1970 to 2009 (Asem \& Alam, 2012)) and to mimic the equity market's performance.

In contrast to these prior studies, our study focuses on the effects of increased flexibility in stock addition to, and deletion from, an Index on the Index's ability to represent and mimic the performance of the underlying market. As such, it is an event study that investigates the effects of increased flexibility on an Index's representation and tracking error by comparing these variables before and after the conversion of the TSX 300. That is, the effect of increased flexibility in stock addition/deletion decision on an Index's functions is an empirical question, and we contribute answers to this question using evidence from converting the TSX 300 Index to the S\&P/TSX Composite Index.

The introduction of S\&P/TSX Composite Index allows the Index Committee to more quickly delete non-performing stocks and to more quickly add stocks that are expected to do well. Stocks can be removed or added on quarterly rather than annual basis, and there is no need to add a stock after a deletion and vice versa. A quicker deletion of non-performing stocks and a quicker addition of stocks that are performing well should lead to stabilizing the proportion of the equity market that is captured by the Index. That is, a non-performing stock may not remain in the Index a whole year and drag down the Index's capitalization or its performance. Similarly, a strong performance stock need not remain outside the Index a whole year until it is added. Also, the ability to quickly delete and add stocks can lead to a better tracking of the equity market, suggesting flexibility should reduce tracking error.

\section{Methodology}

We study the effects of converting the TSX 300 Index to S\&P/TSX Composite Index in May 2002 by partitioning the sample into two sub-periods (January 1992 to April 2002 and May 2002 to December 2011), and comparing the proportion of the equity market that is captured by the Index in the two periods as well as the closeness of the Index return to the equity market's return in these periods. We proxy the Canadian equity market by TSX common equities listed in the Canadian Financial Market Research Centre (CFMRC) database. We compute the Index's (equity market's) capitalization by multiplying shares outstanding by the closing price and summing over all common stocks in the Index (equity market). To compare the proportion of the equity market that is captured by the Index, we first calculate the monthly ratio of the Index's capitalization to the equity market's capitalization over our sample period. We then compute the mean monthly ratio for the period before and after the conversion of the Index, and use t-test to test for a difference in means between the two sub-periods. If the mean is significantly greater for one sub-period, it suggests that the Index captured a higher percentage of the equity market's capitalization in that period.

Time variation in the capitalization of stocks that survived the sample period can drive a difference in the proportions of the equity market captured by the index before and after the conversion. For instance, the Index 
would capture a higher fraction of the equity market after the introduction of the S\&P/TSX Composite Index if the capitalization of the survived stocks increased relative to the equity market during this period. To preclude this possibility, we partition the Index into four portfolios: (i) stocks that survived the entire period, (ii) stocks that were added to the Index, (iii) stocks that were deleted from the index, and (iv) stocks that were discretionary deleted from the index, and we repeat the analysis for these portfolios to ascertain the sources of any difference in the proportions of the market capitalization captured by the Index before and after the S\&P/TSX Composite Index was introduced (Note 3).

Next, we test the Index's ability to mimic the equity market's performance in the two sub-periods in two ways. First, we compute the Pearson correlation between the Index's return and the equity market's return before and after the conversion, and test the difference in the correlations. We use Fisher's $Z$ transformation to test the difference in the Pearson correlation coefficients (Note 4). A higher correlation coefficient for a particular period indicates a stronger co-movement between the Index and the market returns in that period. Second, we compute the tracking error of the Index before and after the conversion. The Index's (market) return is calculated by the mean value-weighted returns of all stocks in the Index (Canadian Financial Market Research Centre (CFMRC) listed on the TSX). Tracking error is computed as the standard deviation of the differences in the monthly Index and the market returns. A lower tracking error for a particular period indicates the Index's return tracks the equity market's return more closely in that period.

Last, we shed light on whether stock additions to, or deletions from, the Index are driven by the performance of the stocks by examining the returns of added and deleted stocks three, two, and one year prior to the addition/deletion events. An upward trend in the returns of the added stocks and a downward trend in the returns of deleted stocks would indicate stock performance has a strong influence on the decision to add and delete stocks, respectively.

\section{Data and Description}

We obtain monthly return and price information from the CFMRC database, and TSX E-Review is used to determine the stocks that were added to and deleted from the Index from January 1992 to December 2011.

Figure 1 shows the yearly distributions of the deletion and addition events over our sample period. We see that both events vary over time. Deletions range from a high of 82 in 2002 (when the index was converted) to a low of 7 in 2010. In total 786 deletions occurred. Additions range from a low of 13 in 2008 to a high of 95 in 2005 (when the Standard \& Poor's announced that income trusts are permissible in the Index, and added 73 income trusts). In total 739 stocks were added.

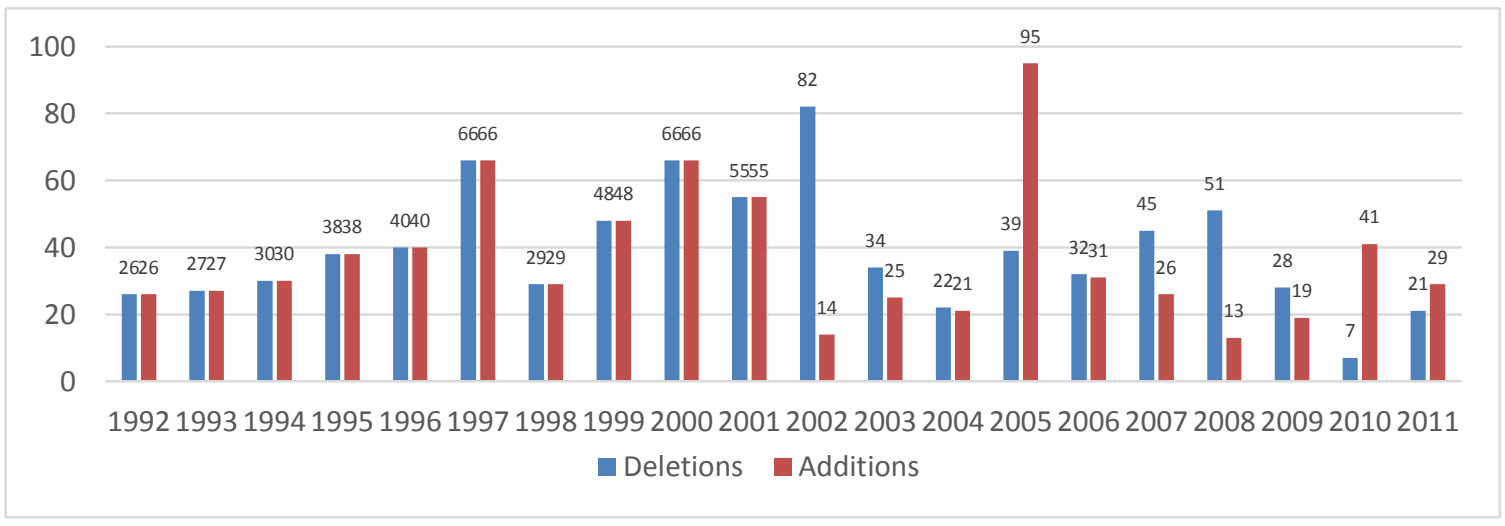

Figure 1. Number of stock added to and deleted from the index in each year

Panel A of table 1 shows the frequency of deleting and adding stocks. From a total of 786 deleted stocks, 714 distinct stocks were deleted from the Index. From a total of 739 added stocks, 661 distinct stocks were added to the Index. Thus, some stocks were repeatedly deleted or added to the Index as the table shows. In the extreme, one stock was deleted from the Index four times and six stocks were added to the Index three times.

Regarding deletions, some stocks were deleted due to natural economics occurrences such as mergers, acquisitions, and bankruptcies. Accordingly, we partition the deleted stocks into stocks that were deleted due to economic events and those that were deleted at the discretion of the Index Committee. Panel B of table 1 
displays the stocks that were added to, deleted and discretionary deleted from the Index as well as the stocks that survived in the Index over our sample period.

Table 1. The frequency of stock addition to and deletion from the TSX 300 Index and the S\&P/TSX Composite Index from 1992 to 2011

\begin{tabular}{|c|c|c|c|c|c|c|c|}
\hline \multicolumn{8}{|c|}{ Panel A: Frequency of Stock Additions and Deletions } \\
\hline & \multicolumn{4}{|c|}{ Deletion Events } & \multicolumn{3}{|c|}{ Addition Events } \\
\hline Frequency of Events & 1 & 2 & 3 & 4 & 1 & 2 & 3 \\
\hline Number of stocks & 648 & 61 & 4 & 1 & 589 & 66 & 6 \\
\hline Total & 648 & 122 & 12 & 4 & 589 & 132 & 18 \\
\hline \multicolumn{8}{|c|}{ Panel B: Additions/Deletions Before and After the S\&P/TSX Composite Index } \\
\hline & \multicolumn{3}{|c|}{$\begin{array}{c}\text { TSX } 300 \text { Index } \\
\text { (January 1992- April 2002) }\end{array}$} & \multicolumn{4}{|c|}{$\begin{array}{l}\text { S\&P/TSX Composite Index } \\
\text { (May 2002-December 2011) }\end{array}$} \\
\hline Number of months & \multicolumn{3}{|c|}{124} & \multicolumn{4}{|c|}{116} \\
\hline Added stocks & \multicolumn{3}{|c|}{428} & \multicolumn{4}{|c|}{311} \\
\hline Deleted stocks & \multicolumn{3}{|c|}{428} & \multicolumn{4}{|c|}{358} \\
\hline Discretionary deleted Stocks & \multicolumn{3}{|c|}{176} & \multicolumn{4}{|c|}{204} \\
\hline Survived Stocks & \multicolumn{3}{|c|}{87} & \multicolumn{4}{|c|}{95} \\
\hline
\end{tabular}

\section{Results}

\subsection{The Proportion of the Equity Market Captured by the Index}

In this section, we compare the fraction of the Canadian equity market that is captured the TSX 300 Index and the S\&P/TSX Composite Index to ascertain the effect of flexibility on the Index's representation of the equity market. Figure 2 plots the monthly percentage of the equity market's capitalization captured by the Index. The percentage increases from 58\% in 1992 to $83 \%$ in 2011 and it trends upward more before the conversion of the Index. Furthermore, the percentage is more volatile before the conversion. This higher volatility is likely due to the lower frequency of stock addition to, and deletion from, the Index during this period (updates to the index occur annually rather than quarterly). As such, stocks that are non-performing and losing capitalization tend to stay in the Index longer resulting in more dramatic changes in the proportion of the equity market that is captured by the Index when revisions occurred. We calculate the standard deviation of the proportion of the market that is capture by the Index, and find it to be 0.0769 before the conversion and 0.0354 after.



Figure 2. The monthly proportion of the Canadian equity market captured by the index

Second, we note that while the number of stocks in the Index fell from 300 to 232 in 2002 when the S\&P/TSX Composite was introduced, the percentage of the equity market that is captured by the Index actually increased during the year (increasing from 74.1\% in April 2002 to 78.8\% in December 2002). The fraction of the equity market captured by the Index increases in 2005 when income trusts were permitted in the Index. In that year, 95 stocks were added to the Index while 39 were deleted resulting in net addition of 56 stocks. Excluding income trusts, the proportion of the equity market captured by the Index increases from an average of $68.22 \%$ before to 77.72 after the introduction of the S\&P/TSX Composite Index. Overall, it appears that flexibility enhances the 
proportion of the market captured by the Index as well as reduces its volatility.

\subsection{Correlation of the Index Return and the Equity Market Return}

In this section, we compare the performance of the Index to that of the equity market before and after the conversion of the Index. Figure 3 plots the monthly value-weighted return for the Index and the Canadian equity market. It shows that the equity market return is more volatile than the Index return, reflecting the effect of small stocks on the equity market return; they are more sensitive to advancing and declining markets.

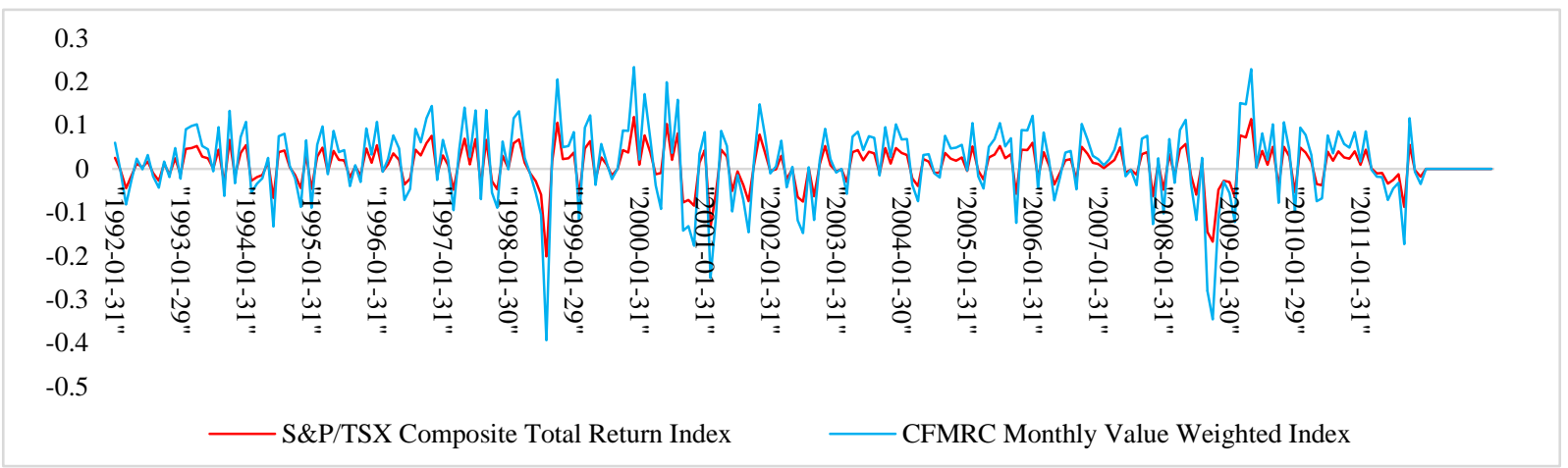

Figure 3. Monthly value-weighted returns of the TSX 300/S\&P/TSX composite index and the Canadian equity from 1992 to 2011

Next, we compute the Pearson correlation coefficient between the Index return and the equity market return before and after the S\&P/TSX Composite Index was introduced. Table 2 reports the results. The correlation is 0.983 before the introduction and is 0.992 after, and test that the two correlations are equal is rejected at the $1 \%$ level of test (i.e., Fisher's $Z$ statistic $=2.89$ ). This suggests that the returns for the Index and the equity market co-move more after, than before, the S\&P/TSX Composite Index was introduced. This result is robust to the exclusion of income trusts, where test shows that the correlation after, 0.993 , is still higher than the correlation before (Fisher's $\mathrm{Z}$ statistic for test of equality $=3.411$, significant at the $1 \%$ level of test). It appears that flexibility in deletions after the conversion enhances the correlation. In particular, quicker deletions after the conversion results in removing non-performing stocks before their performance becomes poorly correlated with the market.

Table 2. Pearson correlation coefficient of the Index and the Canadian equity market returns

\begin{tabular}{ccccc}
\hline TSX 300 Index (1992-Apr. 2002) & \multicolumn{2}{c}{ S\&P/TSX Index (May 2002-2011) } & \multicolumn{2}{c}{ Z-statistic for Difference } \\
(A) & (B) & Without Income Trust (C) & (A) - (B) & (A) - (C) \\
\hline $0.983^{* * *}$ & $0.992^{* * *}$ & $0.993^{* * *}$ & $2.89^{* * *}$ & $3.411^{* * *}$ \\
\hline
\end{tabular}

The table displays the Pearson correlation coefficient between the Index return and the Canadian equity market return (return on all common TSX stocks listed in the CFMRC database).

*** indicates significance at the $1 \%$ level of test.

\subsection{Closeness of the Index and the Equity Market Returns}

In this section, we investigate whether the Index return is more proximal to the market return after the conversion to the S\&P/TSX Composite Index. First, we analyze the difference in the mean returns before and after the conversion. We study both the raw return and risk-adjusted return, computed as $\frac{R_{p}-R_{f}}{\delta_{p}}$, where $R_{p}$ is the return on the Index (market) in a particular month, $R_{f}$ is the return on the month's T-bill, and $\delta_{p}$ is the standard deviation of the monthly Index (market) returns. Second, we calculate the tracking error of the Index returns as the standard deviation of the differences in monthly returns of the Index and the equity market. 
Table 3. The monthly returns of the equity market, and the index before and after May 2002

\begin{tabular}{|c|c|c|c|}
\hline & TSX 300 (1996 - Apr 2002) & S\&P/TSX (May $2002-2011)$ & Test of Equality \\
\hline \multicolumn{4}{|c|}{ Panel A: Mean Return Comparison } \\
\hline \multicolumn{4}{|l|}{ Raw Returns } \\
\hline Equity Market & $0.958 \%$ & $0.685 \%$ & \\
\hline Index & $0.910 \%$ & $0.678 \%$ & \\
\hline Difference & $0.048 \%(0.08)$ & $0.007 \%(0.02)$ & $(0.05)$ \\
\hline \multicolumn{4}{|l|}{ Risk-Adjusted Return } \\
\hline Equity Market & $0.120 \%$ & $0.117 \%$ & \\
\hline Index & $0.107 \%$ & $0.115 \%$ & \\
\hline Difference & $0.013 \%[0.68]$ & $0.002 \%[0.02]$ & {$[0.52]$} \\
\hline \multicolumn{4}{|c|}{ Panel B: Comparison of Tracking Error } \\
\hline \multicolumn{4}{|l|}{ Raw Return } \\
\hline Std. of Monthly Differences & $0.0085 \%$ & $0.0054 \%$ & $2.41^{* * *}$ \\
\hline \multicolumn{4}{|l|}{ Risk-Adjusted Return } \\
\hline Std. Monthly Differences & $0.1839 \%$ & $0.1298 \%$ & $2.02^{* * *}$ \\
\hline
\end{tabular}

The table shows the mean monthly market and Index raw and risk-adjusted returns in panel A. Panel B shows the tracking errors in returns, computed as the standard deviation of the differences in the monthly returns for the Index and the equity market. T-test (reported in bracket) is used for testing the difference in means and Jobson and Korkie's z-statistic (reported in square bracket) is used for the difference of risk-adjusted returns. F-tests are used to test differences in tracking error.

${ }^{* * *}$ indicates significance at the $1 \%$ level of test.

Panel A of Table 3 reports the results for the mean returns. The mean monthly raw return is $0.958 \%$ for the market and $0.910 \%$ for the Index before the Index conversion, and test that the means are equal is not rejected $(\mathrm{t}$-value $=0.08)$. After the conversion, the mean return is $0.685 \%$ for the equity market and $0.678 \%$ for the Index and, again, test that the means are equal is not rejected ( $\mathrm{t}$-value $=0.02$ ). Furthermore, test that the differences in means are equal is not rejected ( $\mathrm{t}$-value $=0.05$ ). Results based on the risk-adjusted returns are similar. Thus, the mean returns of the TSX 300 and the S\&P/TSX Composite Indexes are similar to the equity market returns.

Next, we turn to analyzing the tracking error of the Index. Panel B of Table 3 shows that the tracking error based on raw returns is $0.0085 \%$ before and $0.0054 \%$ after the Index conversion. Test that the errors are equal based on variance ratio test is rejected at the $1 \%$ level of test (i.e., $\mathrm{F}(123,115)=2.41$ ). The results for adjusted returns are similar. Thus, it appears that flexibility in stock addition to, and deletion from, the Index enhances the Index's ability to track the equity market performance (Note 5).

\subsection{Performance and Stock Additions/Deletions}

In this section, we analyze the returns in one, two, and three years prior to stock deletions and additions to investigate the role of stock performance in these events. Table 4 presents the mean returns for the added, deleted, and discretionary deleted stocks. Panel A reports the results prior to the Index conversion and panel B reports the results after. Form panel A, we see that the return of the added stocks increase as the addition event gets closer (e.g., the risk-adjusted returns of the added stocks are $0.26 \%, 0.34 \%$, and $0.48 \%$ in the three, two, and one year to the additions). For the deleted stocks, however, the returns decline as the events get closer, especially, for discretionary deletions. For these stocks, the risk-adjusted returns are $-0.10 \%,-0.15 \%$, and $-0.27 \%$ in three, two, and one year to the deletions. The results from panel B are similar. Thus, it appears the stock performance is important in the decision to add or delete stocks from the Index.

Table 4. Mean monthly abnormal returns

\begin{tabular}{llll}
\hline & 3 Years & 2 Years & \\
\hline Panel A: Prior to the Conversion of the Index (Jan. 1992 to April 2002) & & \\
Raw Returns & & & \\
Additions (1) & $4.99 \%^{2,3}$ & $6.23 \%^{2,3}$ & $7.38 \%$ \\
Deletions (2) & $0.91 \%$ & $0.76 \%$ & $0.84 \%$ \\
Discretionary Deletions (3) & $0.95 \%$ & $0.76 \%$ & $0.63 \%$ \\
Risk-Adjusted Returns & & & $0.48 \%$ \\
Additions (1) & $0.26 \%$ & $0.34 \%$ & $0.06 \%$ \\
Deletions (2) & $0.04 \%$ & $0.04 \%$ & $-0.27 \%$ \\
Discretionary Deletions (3) & $-0.10 \%$ & $-0.15 \%$ & \\
\hline
\end{tabular}




\begin{tabular}{lccc}
\hline Panel B: After the Conversion of the Index & (May 2002 to Dec. 2010) & & \\
Raw Returns & & & $5.09 \%^{2,3}$ \\
Additions (1) & $2.58 \%^{2,3}$ & $3.77 \%^{2,3}$ & $1.35 \%^{3}$ \\
Deletions (2) & $1.61 \%^{3}$ & $1.47 \%^{3}$ & $-3.94 \%$ \\
Discretionary Deletions (3) & $-0.01 \%$ & $-2.05 \%$ & \\
Risk-Adjusted Returns & & & $0.51 \%$ \\
Additions (1) & $0.21 \%$ & $0.33 \%$ & $0.14 \%$ \\
Deletions (2) & $0.12 \%$ & $0.13 \%$ & $-0.37 \%$ \\
Discretionary Deletions (3) & $-0.13 \%$ & $-0.21 \%$ & \\
\hline
\end{tabular}

The mean monthly percentage returns of survived, added, deleted, and voluntarily deleted stocks in the 1,2 , and 3 years leading up to the events.

$2,3,4$ indicate that the mean is different from the mean in portfolio $2,3,4$ at the $5 \%$ level based on t-tests of the difference in means.

\section{Summary and Conclusion}

Major Indices such as S\&P 500 and TSX 300 fulfill dual roles of acting as a performance benchmark and representing their respective equity markets. In May 2002, the TSX 300 was converted to S\&P/TSX Composite Index along with changes that increased the flexibility of stock additions to, and deletions from, the Index. These changes include floating the number of stocks in the Index (no longer required to be 300), increasing the frequency of stock addition/deletion events from yearly to quarterly, and consolidating the number of industrial sectors to 10, down from 14 sectors. We investigate whether these changes result in an increase in the proportion of the Canadian equity market captured by the Index and in a reduction in the Index's tracking error.

Our results show that the Index captures a higher proportion of the Canadian equity market after the Index conversion. Furthermore, the proportion of the equity market captured by the new Index is less volatile than the proportion captured by its predecessor. These results were obtained despite the lower number of stocks in the new Index. Thus, it appears that the increased flexibility in stock additions to, and deletions from, the Index is a key factor in the better representation of the Canadian equity market by the Index. In particular, the Index Committee is able to more quickly remove non-performing stocks from Index, minimizing the effect of their poor capitalization on the proportion of the market captured by the Index.

Turning to the Index's ability to mimic the equity market return, we find that the correlation between the Index's return and the equity market return increases after the Index conversion and the Index's tracking error declines. As mentioned earlier, these improvements are obtained with a lower number of stocks in the Index. Overall, our results suggest that flexibility in the decision to add stocks to, and delete stocks from, the Index contributes to the Index's ability to represent the Canadian equity market and to mimic the equity market's return.

\section{References}

Asem, E., \& Alam, S. (2012). The role of the S\&P 500 Index constituents in tracking the US equity market. International Journal of Economics and Finance, 4(12), 15-22, http://dx.doi.org/10.5539/ijef.v4n12p15

Beneish, M. D., \& Whaley, R. E. (1996). An anatomy of the "S\&P Game": The effects of changing the rules. Journal of Finance, 51(5), 1909-1930. http://dx.doi.org/10.2307/2329543

Bloom, R., \& Blackwell, R. (2009). TSX 300 to be scrapped - The Globe and Mail. Retrieved April 20, 2015, from http://www.theglobeandmail.com/report-on-business/TSX-300-to-be-scrapped/article1172130/

Blume, M., \& Edelen, R. (2004). On Replicating the S\&P 500 Index. Journal of Portfolio Management, 30, 37-46. http://dx.doi.org/10.3905/jpm.2004.412317

Chen, H., Noronha, G., \& Singal, V. (2004). The price response to S\&P 500 Index additions and deletions: Evidence of asymmetry and a new explanation. Journal of Finance, 59(4), 1901-1930. http://dx.doi.org/10.1111/j.1540-6261.2004.00683.x

Foster, R., \& Kaplan, S. (2001). Creative destruction: Why companies that are built to last underperform the market--And how to successfully transform them. New York: Random House.

Hegde, S. P., \& McDermott, J. B. (2003). The liquidity effects of revisions to the S\&P 500 Index: An empirical analysis. Journal of Financial Markets, 6(3), 413-459. http://dx.doi.org/10.1016/S1386-4181(02)00046-0

Income Funds. (n. $\quad$ d.). Retrieved April 26, 2015, from http://www.investinganswers.com/financial-dictionary/income-dividends/income-funds-969 
Jain, P. C. (1987). The effect on stock price of inclusion in or exclusion from the S\&P 500. Financial Analysts Journal, 43(1), 58-65. http://dx.doi.org/10.2469/faj.v43.n1.58

Jobson, J. D., \& Korkie, B. M. (1981). Performance Hypothesis Testing with the Sharpe and Treynor Measures. The Journal of Finance, 36, 889-908. http://dx.doi.org/10.2307/2327554

Lynch, A. W., \& Mendenhall, R. R. (1997). New evidence on stock price effects associated with changes in the S\&P 500 Index. Journal of Business, 70(3), 351-382. http://dx.doi.org/10.1086/209722

Shleifer, A. (1986). Do demand curves for stocks slope down? Journal of Finance, 41(3), 579-590. http://dx.doi.org/10.1111/j.1540-6261.1986.tb04518.x

Siegel, J. J., \& Schwartz, J. D. (2006). Long-term returns on the original S\&P 500 companies. Financial Analysts Journal, 18-31. http://dx.doi.org/10.2469/faj.v62.n1.4055

Wurgler, J., \& Katia, Z. (2002). Does arbitrage flatten demand curves for stocks? Journal of Business, 75, 583-586. http://dx.doi.org/10.1086/341636

\section{Notes}

Note 1. See S\&P/TSX Canadian Indices methodology (2011) at http://www.spindices.com for more details.

Note 2. Several studies have supported the following hypotheses: imperfect substitutes hypothesis (Shleifer, 1986; Beneish \& Whaley, 1996; Lynch \& Mendenhall, 1997; Blume \& Edelen, 2001; and Wurgler \& Zhuravskaya, 2002); price pressure hypothesis (Harries \& Gurel, 1986); certification hypothesis (Jain, 1987); liquidity hypothesis (Hedge \& McDermott, 2003); and investor awareness hypothesis (Chen, Noronha, \& Singal, 2004). Reviewing the above-mentioned studies is beyond the scope of this research, since we are not considering the effects of Index revisions on the stock's prices.

Note 3. The portfolio of survived stocks consists of the stocks that remained in the Index for the specified period. The added portfolio consists of the stocks that are added to the Index in the period and are analyzed only when they are members of the Index. Similarly, the deleted portfolio includes the stocks that are deleted in the period and are analyzed only when they were still members of the Index. Discretionary deleted stocks are the stocks that are deleted based on the discretion of the Index committee.

Note 4. One of the implications of $\mathrm{Z}$ transformation is testing for equality of two population correlations. To examine the equality of two independent populations' correlations, $\rho_{1}$ and $\rho_{2}$, we first transform two sample correlations, $r_{1}$ and $r_{2}$ which are computed from two independent samples of $n_{1}$ and $n_{2}$ observations, to $z$-score: $\mathrm{Z}_{\mathrm{r}}=\frac{1}{2} \log \frac{1+r}{1-r}$, under the null hypothesis that the population correlations are equal. The following has approximately a standard normal distribution: $Z=\frac{Z_{1}-Z_{2}}{\sqrt{\frac{1}{n_{1}-3}+\frac{1}{n_{2}-3}}}$

Therefore, if the above quantity is greater than 1.96 or less than -1.96 , the two correlations are significantly different at $5 \%$ level of significance.

Note 5. While we are able to analyze different portfolios of the Index (survived stocks, added stocks, deleted stocks) to ascertain the source of increase in the market capitalization captured by the Index, we are not able to do the same for correlations or tracking errors since returns diversify. For instance, the tracking errors of these portfolios are all larger than the Index's tracking error both before and after the conversion of the TSX 300 to the S\&P/TSX Composite Index. This is because the returns of these portfolios diversify and in the aggregate produce lower tracking errors. Thus, it is hard to assign the reduction in tracking error to a particular portfolio of the Index.

\section{Copyrights}

Copyright for this article is retained by the author(s), with first publication rights granted to the journal.

This is an open-access article distributed under the terms and conditions of the Creative Commons Attribution license (http://creativecommons.org/licenses/by/3.0/). 